\title{
Internationalization at Home and the Development of the Linguistic Skills of Written Expression and Reading Comprehension in Foreign Language Teaching
}

\author{
Adrián J. Acosta Jiménez \\ Universidad Autónoma de Madrid, Spain \\ Yolanda García Hernández
}

Universidad Autónoma de Madrid, Spain

\begin{abstract}
The emergence of COVID19 on the world scene has become a major challenge for the entire society and, in this particular case for the methods used in teaching and learning foreign languages in Higher Education Institutions. Not only teachers but also students have had to suddenly face the need to achieve their linguistic and intercultural academic goals in a totally new environment, characterized by the massive presence of digital and online teaching tools and by a very big lack of motivation in both teachers and students. In this study, we will analyze the relevance of virtual exchange and collaborative learning with foreign students who remain in their home universities and their contribution to improve the skills included in the CEFR. Starting with a case study of foreign language tuition in German and based on qualitative data, we will show the usefulness of internationalization at home as an effective tool for the development not only of linguistic skills, such as the written expression and reading comprehension, but also of the necessary intercultural competence. Furthermore, we will also examine how internationalization at home can be an equally useful tool or teaching practice to foster motivation in foreign language learning and teaching. We will highlight the relevance of teaching practices and resources at a time when teachers and students have had to get used to new teaching practices overnight. Based on the provided data, and due to its pedagogical relevance, we will be ready to conclude that internationalization at home is a practice that has offered an answer to a problem arising after the imposition of the lockdown and consequently should continue to be used at HEIs in the future.
\end{abstract}

Keywords: applied linguistics, online teaching and learning, internationalization at home, foreign languages, writing skill

\section{Introduction}

\section{Literature Review}

The sudden and unexpected outbreak of the COVID-19 pandemic in the first months of 2020 confronted the whole society with a unique challenge. Thus, all the different lifestyles reflected in the various professional, social and family scenarios, were affected by the spread 
of the virus and its consequences overnight, and the educational environment was not an exception. The teaching activity in practically all educational centers and at all levels of education changed from its traditional face-to-face methodology to an entirely distance or online system, for which neither the teachers nor the students had previously been prepared. That new scenario therefore required urgent and necessary implementation of new measures and regulations, especially because we - teachers - continued striving to achieve the same learning objectives that had been initially set at the beginning of the course. None of us wanted to lose a whole academic year.

In that new scenario, which mainly involved adapting to a distance teaching/learning system, many teachers chose methodologies, such as streaming lessons, explaining content to their students by showing them slides to their students through different virtual teaching platforms like Microsoft Teams, teaching a reduced version of the syllabus or simply tutoring and accompanying students' autonomous learning. The teachers' lack of knowledge about the proper use of digital tools, their insecurity when making use of them and the uncertainty associated with the first months of the global health crisis often led to a growing lack of motivation among their students and, in many cases, also among teachers themselves: they became gradually discouraged, demotivated and disinterested with respect to their teaching/learning practices. In this regard, numerous studies on the impact of the confinement linked to COVID-19 on the educational environment (Acosta Jiménez, A. J. (2020), Hartshorn, K. James, McMurry, Benjamin L. (2020) and others) have been carried out in recent months. Most of them have highlighted a growing dropout rate by students, along with an important - and in many cases involuntary or unconscious - lack of involvement and commitment of both groups regarding their tasks, obligations and responsibilities within the university environment.

It is at this point that me must make it clear that, when we talk about the rapid transition to virtual teaching, we are referring neither to the digital transformation of teaching through a deep reflection on the part of the teaching staff nor to a greater technological endowment planned by Higher Education authorities or policies. The sudden outbreak of the pandemic did not give teachers the opportunity to prepare themselves or to activate some teacher training. It forced and urged many teachers to provide an imminent response to all those sudden changes and to try to continue with their teaching activities and practices in a safe manner as quickly as possible. We therefore agree with Hodges et al. (2020) when they affirm that the methodological change derived from the emergence of COVID-19 is not exactly an organic digital transformation of teaching and learning, but rather the implementation of an emergency remote teaching methodology that has attempted to make our lives easier in the historical situation in which we all have been - or are still - immersed. García-Peñalvo and Corell (2020) also state that this urgent and fully unexpected situation has revealed many of the main methodological and competency deficiencies in education, and it has also highlighted the profound current difficulties that we teachers have to face when it comes to the necessary digital transformation of Higher Education institutions.

As regards to teaching and learning foreign languages at the university level, we cannot forget about the eminently practical and communicative character of language learning skills. In this sense, the changes and adjustments required for our teaching activity cannot and should not be exactly the same as those that were being applied in many other disciplines at universities. The active participation of students in their own learning process was considered essential and it was therefore urgent to (re)think new and attractive teaching methodologies 
capable of fostering their motivation and involvement in tuition. Thus, neither teachers nor students should conceive technologies as insurmountable barriers or obstacles to learning and to acquiring or developing the different key competencies. The massive incorporation of digital tools in language teaching and learning should rather be understood as an opportunity to break more than ever with the physical barriers of the classroom and to be able to enter new intercultural and multilingual spaces. That adapted teaching reality based on technology offered teachers a new scenario from which we could all benefit. During the COVID-pandemic, the implementation of digital resources and platforms gave us all the opportunity to finally break away from other more traditional teaching methods, to present alternative models of foreign language teaching/learning, and to approach other foreign cultures and get to know them better.

When we talk about (re)thinking foreign language teaching, we teachers must also reflect on how we can maintain the quality levels which were initially set as well as on how we can offer equal opportunities to our students so that they may access those new teaching practices and methodologies and all the various and different materials around it. It is true that nowadays we often take for granted the almost universal access of younger students to technologies and we tend to believe that they all have an adequate mastery of them. Many studies go so far as to speak of "digital natives" when referring to young people and teenagers. However, if we take a closer look at the reality experienced over the last few months and the period of confinement, we can conclude that this is not entirely true. For instance, several studies have shown that not all students have their own electronic devices and they cannot always access synchronous virtual classes; others do not live in houses fitted with internet access or with an adequate signal strength as to be able to follow quality teaching. In other scenarios where the online teaching practices often coexist with the telework of many of the students' relatives, we can see how the personal computer available at home needs to be shared in the family and, consequently, it is not freely available and cannot be used by the student at any time. In the study by Acosta Jiménez (2020), it was observed that 7\% of Bachelor students studying degrees related to foreign languages at the Universidad Autónoma Madrid did not have the required devices to follow classes properly. This lack of accessibility to electronic resources by a significant number of students is very worrying indeed, and it may lead to the creation of gaps and

inequalities in the teaching and learning practices and in the adequate and required acquisition of competencies when learning a foreign language.

When we look at the literature published in relation to teaching in Higher Education in times of the COVID-pandemic, we tend to find a clear emphasis on the response that each institution implemented during the period of confinement; even after the lockdown was over, we appreciate that many institutions implemented a model of blended learning. Most of these studies focus on the typology of the technologies that were used in that online teaching model or on how many facilities were modified during the period of confinement. However, we hardly find any significant analysis of the perception that both teachers and students had of the teaching/learning process itself. As discussed above, Canaza-Choque (2020) states that this transformation of traditional teaching methodologies into others more based on digitalization contains other important and significantly positive aspects. For instance, they have forced us as teachers to use new methods in university teaching as opposed to other more traditional methods and to replace - at least partially - models which have become obsolete. We also agree with him in the conviction that this pandemic and its implications 
in the transformation of teaching and learning can generate a deep demotivation and inequality of opportunities among students, and this is of course an essential aspect that must be addressed by the various academic and political authorities in all countries.

In this context, and being still immersed in a post-pandemic era, it becomes necessary to carry out an analysis of the so-called internationalization at home as a useful tool for the development of key competences in foreign language students, since this internationalization may offer them real learning contexts where they can use the foreign language that they are learning. It will also help us teachers to maintain the quality standards of our teaching practices and may ensure that students achieve all those key competences set by the CEFR. The review and (re)design of our teaching activity should also consider equal opportunities among students and should try to avoid the segregation or creation of disadvantageous spaces for students. Thus, we believe that the novel use of semi-directed language exchanges in an internationalized environment at home and outside the classroom has meant for many teachers and students the creation of a new learning context that plays an undoubtedly important role in the development of key language skills such as written expression, reading comprehension and intercultural competence.

\section{Objectives}

The main objective of this article is to analyse and evaluate the methodological relevance of a semi- directed language exchange used in a language teaching context between native speakers of Spanish and native speakers of German. All students had to practice the different communicative skills in the foreign language while they were immersed in a home-based internationalization environment. Such a practice primarily aimed at improving the linguistic and intercultural competences of learners while they are living with all the constraints and restrictions derived from the COVID-19 crisis and were immersed in blended learning environments.

By semi-directed language exchange, we mean the creation of several tandem conversation groups in which students of different nationalities are integrated together and in which the mother tongue of some students was the target language of others, and vice versa. On this occasion, and due to the mobility restrictions derived from the confinement, we teachers considered appropriate to create an atmosphere of internationalization at home for our students and to join our Spanish students learning German as a foreign language with German students learning Spanish as a foreign language at the UAM and with other German students attending lessons at different German universities. We were therefore able to promote a direct contact and linguistic exchange between native speakers of both languages without making them leave their home university.

With the implementation of the tandem methodology within our teaching practices we aimed to achieve the following specific objectives:

To know how internationalization at home may have an impact or an influence on the achievement of the different linguistic objectives set in each of the language courses taught at university and by the CEFR.

To find out the relevance of the tandem methodology for the acquisition and development of the linguistic skills such as the written expression and the reading comprehension in foreign languages. 
To find out whether the tandem methodology used in an internationalization environment at home may be useful and lead to develop and encourage the intercultural competence of learners of German as a second foreign language.

To facilitate the students' self-regulated participation in the exchange forums concerning different topics, and to enhance and promote the use of their own technological resources, in order to ensure their real possibilities of access to the network without having to incur in inequalities or undesirable technological gaps.

\section{Methodology and research questions}

With the aim of verifying the relevance and all the achievements reached through this tandem methodology, we designed a qualitative research based on the methodology of a case study from which we were able to obtain relevant qualitative information from the different questionnaires that were carried out by the informants, who were the same foreign language students that have been mentioned above.

The key questions that guided our research were always closely related to the different general and specific objectives that have been described above. That is:

Is internationalization at home beneficial for the development of the different key language skills and for the development of the intercultural competence of language students?

To what extent do native Spanish speakers and native German speakers value the tandem methodology and the regular exchange of written messages positively?

Can the relationship between students from different backgrounds in the same learning forum be useful to all of them? May it help them - in a collaborative way - to progress in their proficiency in the written expression and/or in the reading comprehension? Can we observe that both groups of students, Spanish and German, make progress in terms of language proficiency?

May the tandem methodology help the students to get to know better the foreign culture(s) of their tandem partners? Will they be able to become more interculturally competent?

\section{Method - Instrument and context}

The method used for data collection in the research based on the case study method described above was the questionnaire. This instrument was made up of a total of 31 questions that explored aspects such as the demographic characteristics of the informants, their assessment and opinion about the tandem project in general and about the work they did in each of the topics addressed in particular, their motivation to learn and some other aspects linked to acquisition/development of each linguistic competence and of the intercultural competence.

The specific context to which we are referring in this article is linked to our teaching activity as teachers of as a second or third foreign language at a Spanish university. Within that context we managed to implement the tandem methodology between Spanish students of German as a foreign language and German-speaking learners of Spanish as a foreign language. The whole tandem project took place during the period of blended learning triggered by the COVID-19 crisis, that is between March and May 2020.

The project was shown and explained in detail to our students during the first session of tuition in the Spring semester. At that time, a long and interesting discussion was held 
between students and teachers. We all tried to select the different topics that the students were going to work on in the tandem project and the various language exchanges to be established with their classmates and tandem partners. According to their language level and their personal likes and preferences, most students agreed that the most important and motivating topics for them were those related to hobbies and leisure, music and series, the experience of studying abroad, the use and development of language in the Internet age and, finally, all the information about festivals and popular traditions in the foreign culture. All the different groups of students had the opportunity to address and work on each of these topics in the forums and to create a whole and relevant chain of linguistic exchanges. The regular and collaborative work of Spanish and German-speaking students with an equal or very similar level of linguistic competence in the foreign language did not only allow the students to get

to know each other and to develop their language skills, but it also led to an interesting and deep analysis and self-awareness of their own and other people's culture and language.

\section{Participants}

We must consider two main groups of participants and informants within the tandem project that we present in this article.

On the one hand, we have the group of students who had Spanish as their mothertongue. These were students from different bachelor degrees at the Universidad Autónoma Madrid (Bachelor Degrees such as Translation and Interpreting, English Studies, Modern Languages, Culture and Communication, and Hispanic Studies). All these students were studying German as a second - or even as a third -foreign language. The participants - mostly aged between 19 and 22 - had a foreign language proficiency level of around A2/B1 in the CEFR, and all of them were studying in Madrid on a blended learning basis.

On the other hand, we have the group of students who had German as their mother tongue. Most of these students were in Madrid as incoming students within the Erasmus+ international mobility program, but some of them remained in their home cities in Germany and were only planning to come over to Madrid in a near future. These students were studying different bachelor degrees, such as Law, Psychology or Modern Languages. All of them had in their curriculum the study of Spanish as a foreign language and showed a proficiency level of Spanish of at least B1 in the CEFR.

Finally, and although they were not the object of this study, all the teaching staff from the German department of the Faculty in Madrid participated actively in this project too. They were very active in the supervision of the different exchange forums and they also carried out the preparation on each of the topics on which the tandem project was based on.

\section{Data Collection Tool}

The teachers involved in the project worked on a questionnaire elaborated as a data collection tool, and once it was ready, it was made available to all the participants in the project in the last weeks of regular tuition at university. Then, each informant was required to complete all the questions in the data collection tool anonymously and they were given as much time as they needed to do so. 
In addition, and since the questionnaire was conducted through the Google Forms application, all the answers collected were also automatically sent to the teachers' register, which was helpful and saved a lot of time.

\section{Data Analysis - Qualitative data}

Considering the answers given by the students in the questionnaire, we can observe that about $60 \%$ of the informants say that they really liked and enjoyed their active participation in the tandem language exchange project as a tool linked to an internationalization framework at home (5 points out of 5). $31 \%$ of the students rated it 4 out of 5 . In other words, the vast majority of the group (91\%) was very happy or happy with the project and with the positive effect it had had on their language learning process. With this satisfaction, they do not only refer to the cognitive aspect, but they also explicitly refer to other aspects, such as the affective and the motivational factors.

Regarding the different topics that were addressed by the students during their participation in the tandem project, most students stated that those topics had been useful, in order to be able to work collaboratively with foreign students whom they had never met before. These topics also helped them to increase their knowledge of the target learning culture and to develop their linguistic skills. $70 \%$ of the informants rated them as very adequate, whereas $25 \%$ of them rated the topics as adequate. Only 5\% considered that the selected topics had had neither a positive nor a negative influence on their linguistic or intercultural development during their participation in the tandem project.

When assessing the different topics addressed by the students in their language exchanges, we could also find different degrees of interest in each of them:

Music and culture: $81 \%$.

Getting to know each other: $58 \%$

Festivals and popular traditions: 55\%.

Studying abroad: $50 \%$

Learning languages in the Internet age: 39\%.

Students' motivation or lack of motivation was also a particularly important issue for us teachers, since most of the students said in the aforementioned questionnaire that they had often felt somehow unprepared and unmotivated when they had to face a new and totally unexpected reality which was affecting their families, social life and academic situation because of the COVID-pandemic. 


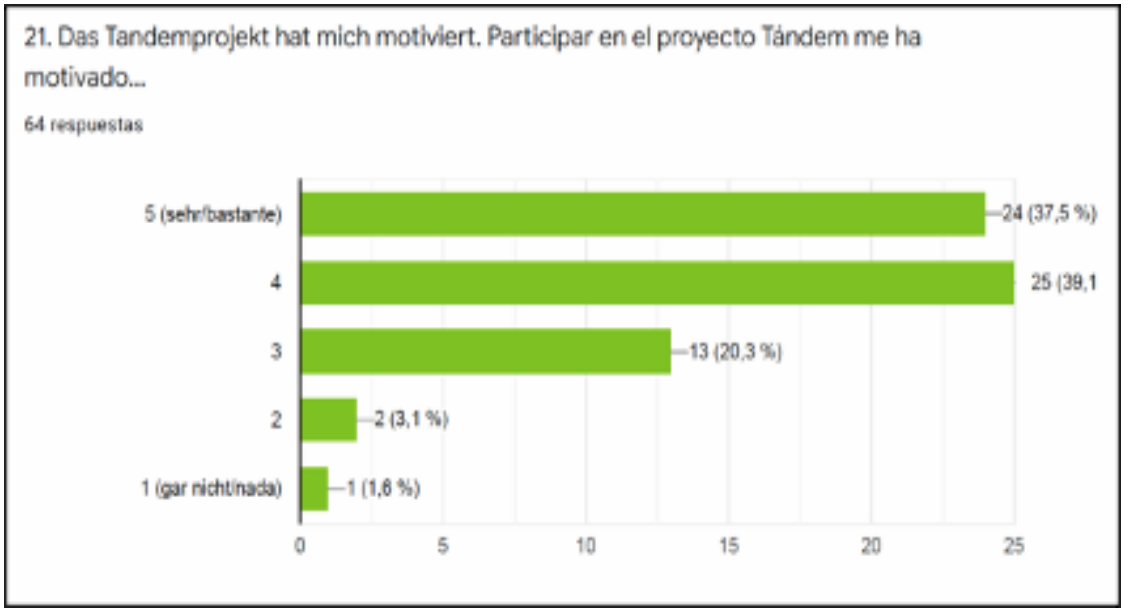

Figure 1

In Figure 1 we see that $77 \%$ of the informants felt very encouraged or encouraged to continue with their German courses after their participation in the tandem project. They considered that it had promoted the real communication in the foreign language and that the contact with native speakers through digital tools had helped them to improve their language and cultural skills.

Many of the questions in the questionnaire used for collecting data also revealed a clear trend towards the positive development of language skills. It is true that some skills were not worked on, such as the oral expression and/or the oral comprehension in the foreign language. We failed to assess the development and evolution of the students in those skills. However, in the questions referring to the development of the reading comprehension skills, $64 \%$ of the informants stated that their active participation in the tandem project had been helpful or very helpful, as shown in Figure 2.

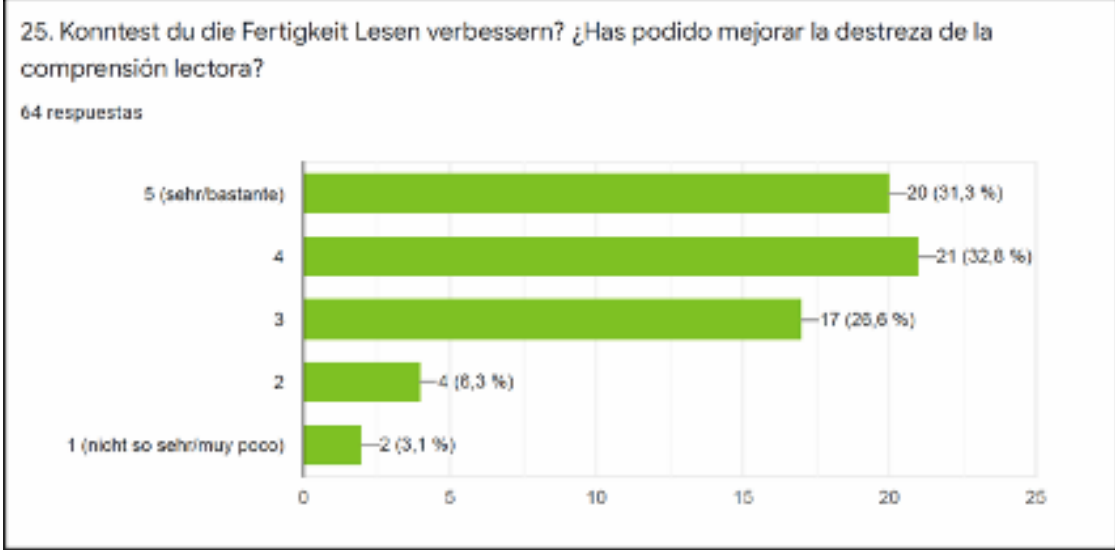

Figure 2

Whereas communication between the native Spanish and German-speaking students was based almost exclusively on the production and comprehension of written texts, these 
competencies are also very much reinforced in the informants' evaluation (see Figure 3). Thus, $25 \%$ of the informants rated their progress in this skill as very positive, and $45 \%$ also answered that the tandem experience had helped them a lot. We can therefore observe that $70 \%$ of the participants had a positive or a very positive assessment of the tandem as a useful method to improve their language proficiency in the foreign language.

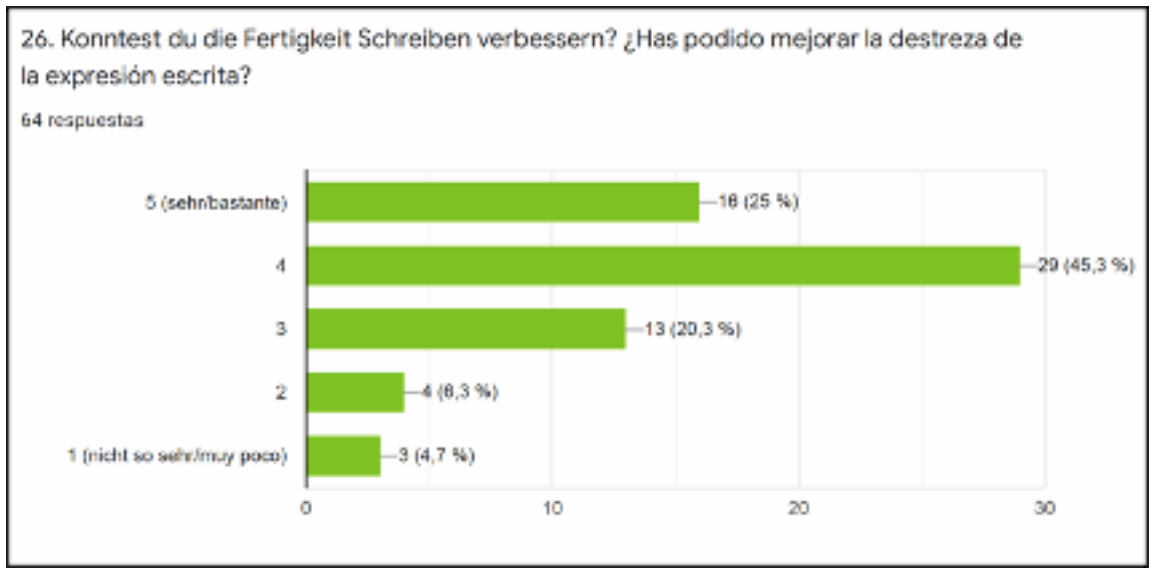

Figure 3

Finally, we would also like to briefly comment the data that refer to the subjective awareness of the participants in the project in relation to their progress in the so-called intercultural competence. $33 \%$ of the informants stated that this experience based on the internationalization at home had been totally adequate to deepen their intercultural competence, not only from a cognitive level, but also from an affective and attitudinal perspective. Likewise, $45 \%$ of the informants gave 4 points out of 5 to the adequacy of this project in terms of having been able to achieve that objective. The data collected in Figure 4 show that $78 \%$ of the students had found the project very useful and convenient to develop their intercultural competence and get to know the foreign culture better.

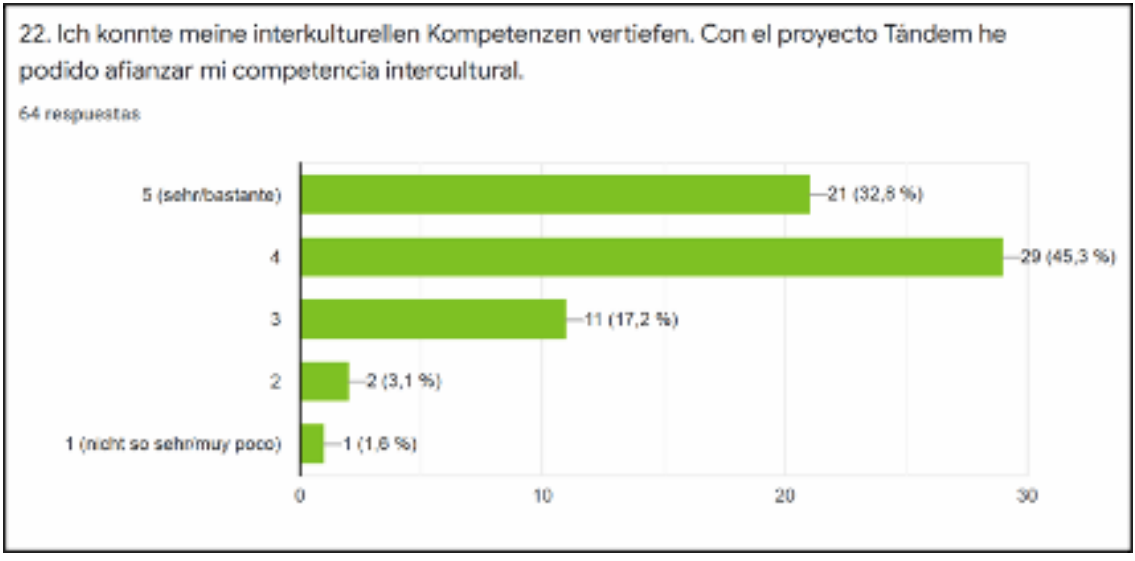

Figure 4 


\section{Evaluation and results}

Having analyzed the qualitative data discussed above and referring back to the proposed objectives at the beginning of this article, we can conclude that the project based on the semidirected language exchange in a home-based internationalization environment has more than fulfilled all the goals that we had originally expected to achieve in this study.

With regard to the first objective, that is the evaluation of internationalization at home as a support for the development of key competencies, we must affirm that the data collected through this study support a very close relationship between the development of linguistic skills and the language and

cultural exchanges between Spanish native speakers learning German and German students learning Spanish, even though some of the latter students remained in their corresponding home universities. There is no doubt that the exchange in an environment involving a total linguistic immersion will always be extremely beneficial. However, in the pandemic scenario in which we are now living, the tandem methodology is proposed as a useful resource of great value for all foreign language learners.

Regarding the development of written comprehension, which was our second specific objective, it has become clear that there is also a close relationship between the use of forums and platforms for real language exchanges and for the development of students' comprehension skills. Their motivation when learning a foreign language significantly grows when they have to deal with authentic texts dealing with topics of interest and when they have to work collaboratively with other students and that is how this key competence may also be reinforced.

The tandem methodology has also been endorsed as a context of exchange in which it is possible to develop the multicultural competence, as we proposed in the third specific objective. It is important to assume here that it is not only a matter of an exchange of knowledge related to the target culture. It is also about developing other competencies that allow for an effective intercultural communication, based on attitudes and on other solid affective factors that allow the existence of a natural, adequate, real and fluent communication in the foreign language.

Finally, and as we mentioned in the fourth specific objective, active and collaborative digital methodologies have been often implemented in the last few months, since they do not require synchronous meetings in the networks, and that makes it possible for each student to interact in the forums when they have the real possibility to do so. Thus, all students have had the same requirements without experiencing disadvantages or limitations for not having the necessary technological resources. These teaching practices have therefore provided the students with an adequate learning autonomy and equal opportunities.

\section{Discussion and limitations of future research}

Leaving aside the necessary mobility restrictions set by the scientific and political authorities in times of COVID-19 pandemic, the implementation of the new teaching models and practices referred to in this article clearly shows that collaborative learning through digital tools among students of different nationalities has a very positive impact on their motivation. It allows them to make a more effective and real use of all the linguistic and intercultural skills that they have acquired and to put their language training into practice in a regular and very 
active way in real multilingual communicative environments. Thanks to these teaching practices in which they can reinforce, consolidate and apply the grammatical structures and vocabulary that they have acquired not only in the language classroom but also in the web and in the tandem practice with foreign students, language learners appear to feel much more attracted to other languages and cultures and that increases and encourages their desire to participate in internationalization experiences both inside and outside their own country.

Nowadays, when international mobility - so necessary for language learners as a complement to their academic training - seems unthinkable or at least it remains subject to very strict limitations, the implementation of teaching methodologies such as tandem experiences allow for an adequate development not only of the key linguistic competencies such as written expression and reading comprehension, oral expression and comprehension, but also of the essential intercultural competence (Bennet, 1986; Deardorff, 2006). In this sense, the limited physical mobility of students in times of the COVID-29 crisis is thus complemented by innovative teaching practices that favor internationalization at home (Beelen and Jones, 2015; Brandenburg, 2014; Fritz, W. and Möllenberg, A.,2002; Robson S., 2017). Moreover, for many students, for whom participation in a physical mobility program to other countries is limited by different factors such as economic, family, personal, work-related factors, etc., immersion in their foreign language classes in certain intercultural and multilingual spaces and their active participation in collaborative learning activities with students from other cultures, offers them a kind of alternative mobility, that is, as a kind of virtual mobility and a certain internationalization within their corresponding home universities.

In summary, the exceptional scenario brought about by the irruption of COVID-19 to the educational environment has highlighted the need to (re)think and implement alternative teaching methodologies in the classroom to the traditional face-to-face teaching. The enormous challenge that

teachers and students have had to face by suddenly having to adapt most of their teaching/learning activities to an online format should therefore be understood not as a handicap, but rather as the opposite; that is, as an opportunity to foster the true internationalization of teaching practices - physical or virtual - favoring the development of all the linguistic and intercultural skills reflected in the CEFR.

The challenge of creating collaborative learning spaces and networks at the various HEIs is now more relevant than ever, and it requires the collaboration of all teachers in the design of new teaching practices, resources and learning and assessment tools, as well as the necessary training of teachers and students in the handling of new technologies.

\section{References}

[1] Acosta Jiménez, A. J. (2020). Estudio empírico sobre la influencia del confinamiento por la COVID19 en la enseñanza de lenguas extranjeras en la educación superior: herramientas y resultados de aprendizaje. En: Guarro Pallás, A. (Presidente). XI Congreso Iberoamericano de Docencia Universitaria. La transformación digital de la universidad. Asociación Iberoamericana de Didáctica Universitaria (AIDU), San Cristóbal de La Laguna, España. 
[2] Beelen J., Jones, E. (2015). Redefining Internationalization at Home. In Curaj: Adrian et al. (eds), The European Higher Education Area, Between critical reflections and future policies, 59-72.

[3] Bennett, M.J (1986). Towards ethnorelativism: A developmental model of intercultural sensitivity. In: Paige RM, editors. Cross-cultural orientation: New conceptualizations and applications. New York: University Press of America, 2770 .

[4] Deardorff, D.K. (2006). Identification and Assessment of Intercultural Competence as a Student Outcome of Internationalization. In: Journal of Studies in International Education, Vol. 10 (3), 241-266.

[5] Fritz, W., Möllenberg, A. (2002). Measuring Intercultural Sensitivity in Different Cultural Contexts. In:

[6] Intercultural Communication Studies XI, Vol. 2, 165-176.

[7] García-Peñalvo, F. J.; Corell, A. (2020). La CoVId-19: ¿enzima de la transformación digital de la docencia o reflejo de una crisis metodológica y competencial en la educación superior? Campus Virtuales, 9(2), 83-98.

[8] Hartshorn, K. James, McMurry, Benjamin L. (2020). The Effects of the COVID19 Pandemic on ESL Learners and TESOL Practitioners in the United States. In: International Journal of TESOL Studies, Vol. 2 (2), 140-156.

[9] Hodges, C., Moore, S., Lockee, B., Trust, T. y Bond, A. (2020). The Difference Between Emergency Remote Teaching and Online Learning. Recuperado de: https://er.educause.edu/articles/2020/3/the-difference-betweenemergency-remote- teaching-and-online-learning.

[10] Robson, S. (2017). Internationalization at home: internationalizing the university experience of staff and students. Educaçao, Vol. 40(3), 368-374. 